\title{
Low-carbon Economy Development Status and Countermeasures in Jilin
}

\author{
Li Bai \\ Jilin Institute of Chemical Technology Economics and Management School Jilin, China \\ blas@tom.com
}

Keywords: Low-carbon economy; Status; Jilin City; Countermeasures

\begin{abstract}
In 2008, Jilin City became one of the first low-carbon economy development pilot cities in China officially. From then on the low-carbon economy development status had become a hot issue in Jilin. This paper analyzes the low-carbon economy development status in Jilin City and proposes countermeasures to solve the problems.
\end{abstract}

\section{Introduction}

Low-carbon economy is an economic model based on low energy consumption, low pollution and low emission, which is another major progress of human society following the agricultural civilization and industrial civilization, its essence is the efficient use of energy, the clean energy development and the pursuit of green development, its core is energy technology and emissions reduction technology innovation, industrial restructuring and institutional innovation, and the fundamental shift of human survival and development concept, its objective is to strive for the least greenhouse gas emissions, while the maximum output of the entire society, in order to mitigate the climate change and promote sustainable development of human society.

It was in 2003 the UK published its Energy White Paper which is called "Our energy futurecreating a low carbon economy" that "Low-carbon Economy" was seen in government documents for the first time. In October 2006 the British government issued the "Economics of Climate Change: Stern Report", and called for a global transition to the low-carbon economy, the main measures included: improving energy efficiency; of energy sectors such as electricity department, establishing strong price mechanism, global alliance for research and development and deployment of decarburization hightech and so on. In 2007 several China-EU research institutions strongly recommended to strengthen cooperation between China and the EU based on a detailed analysis of interdependence between China-EU energy security and climate security, and proposed to set up several low-carbon development demonstration areas in China, attempting to provide demonstration basis for policy formulation of promoting low-carbon economy development by these demonstration areas. In fact, the economic situation of different regions in China is indeed distinct, natural resource endowments, economic growth speed and development and export opportunities are all different, so it does need to establish low-carbon economy development mode through the establishment of low-carbon economy development demonstration areas, and take it as a reference to promote the construction of the national low-carbon economy. So in 2008, Jilin City officially became one of the first low-carbon economy development pilot cities in China.

\section{Low-carbon Economy Development Status in Jilin}

\section{Economic Development Status in Jilin}

Jilin City locates in the northeast of China, has the corresponding land area as Belgium, and has a population of 4.5 million which is approximately equal to the population amount of New Zealand. It is the second largest city of Jilin Province and accounts for a quarter of the GDP of Jilin Province. Since the nineties of last century, Jilin City has a rapid economic growth and GDP average growth rate achieved 10.6\% during 1990 to 2007, especially between 2000 and 2007 GDP increased at $11.6 \%$ which is such an alarming rate of growth. 
Jilin City is rich in forestry resources, water resources and arable land resources, so it is an important food processing base; at the same time it has a large number of natural, metal and mineral industries. In addition, China's first commercial hydroelectric power project which is called Fengman dam is located in Jilin City. The main industries of Jilin City are petrochemical, metallurgy, automobiles, energy, agricultural products processing, traditional Chinese medicines and biological pharmaceuticals, electronics, information technology and equipment manufacturing and so on. Among them, the four pillar industries are: petrochemical, automobile manufacturing, metallurgy and electrical power. Major industrial products of Jilin City are steel, cement and vinyl.

\section{Low-carbon Economy Development in Jilin}

In the "Low-carbon Development in Jilin City" scenario, carbon emissions in Jilin City would be reduced to $60 \%$ of the baseline scenario which is without climate change countermeasures by 2030 . But according to the assessment results, Jilin City is still far from the goal of low-carbon economy. Currently carbon-productivity in Jilin (GDP amount per unit of CO2) is about half of the national average amount, and according to the estimating standard of Chinese Academy of Social Sciences, exceeding the average level of $20 \%$ can be identified as "low-carbon". In 2007, the carbon emission per capita in Jilin City is 2.5 times than the national average, which is far from the goals of development plans.

The leaders at all levels of Jilin City have been fully aware of the importance of developing lowcarbon economy, and have made many efforts for the development of low-carbon economy in the Eleventh Five-Year Plan period such as reducing the dependence on heavy industry, and have made remarkable achievements in the renewable resources, energy efficiency and public transport. In addition, in Jilin's Twelfth Five-Year Plan, the Government has targeted for low-carbon economic development path with emphasis, and has pointed out many possible measures in policy development, technology development, energy conservation, structural adjustment and other aspects. It is said that the construction of three hydropower station with total installed capacity of 12.4 million kilowatts has been included in the construction plan of Jilin City; in the Twelfth Five-Year Plan period, the wind power would be increased of $0.5 \mathrm{GW}$, and as to biomass power generation, Jilin City is planning to build a 25,000 kilowatts direct-fired biomass power plant model in large-scale food processing district in order to explore the construction of several 100 or 200 kilowatts small power plants in the village. In addition, a nuclear power project which has the capacity of 4,000 megawatts is also drafted.

\section{Difficulties of Developing Low-carbon Economy in Jilin}

\section{The public is lack of low-carbon consciousness.}

Although the project of low-carbon economy model city of Jilin had been launched in 2008, lowcarbon economy is still a very strange concept for the general public. The public don't understand the meaning of low-carbon economy, don't know the path to achieve the low-carbon economy, not to mention to take actions to build low-carbon city. Lack of basic knowledge and understanding of low-carbon economy of the public is bound to hinder the implementation of government policies and the extension of business countermeasures to promote low-carbon economy development, and in the meanwhile is not in favor of taking active national action by the public.

\section{The industrial structure is not reasonable.}

As most of our inland provinces and cities, Jilin's industrial structure relies on the rapid growth of industrial production which spurs the city's economic growth. Under such structure, agriculture gradually declines in the proportion of the total economic aggregate, but the industry remains a high proportion of total economic aggregate, at the same time, service industry develops slowly and remains a low proportion of total economic growth. Such kind of structure brings two obvious results: Firstly, the rapid development of industry inevitably leads to immense pressure for the environment, especially in Jilin City which regards the petrochemical, automobile manufacturing, metallurgy and power industry as the leading industrial, the industrial processes must produce large amounts of 
carbon emissions inevitably; Secondly, such kind of industrial structure is not conductive to rapid economic growth and rapid development of society. The only way to achieve modern production of agriculture and industry is to vigorously develop service industry in order to create more material wealth.

The technique level of high energy-consuming enterprises is still low.

The proportion of production equipments operating currently in Jilin City which can reach the international advanced level is less than $10 \%$. Therefore, we need to draw up a specific plan to accelerate the technology transformation and equipments upgrades. Currently it is the rapid development stage of industry, especially the heavy chemical industry, which brings heavy burden and severe pressure on China's low-carbon economy development.

\section{Energy structure needs adjustment.}

Current energy structure is based on coal and oil which is the constraint factor to develop lowcarbon model. Currently over half of the production and consumption of primary energy is still coal and oil, which is difficult to change in the present and the future for a long period of time. As economy development, the demand for energy will grow and the consumption of coal and oil will also increase, which leads to the emission increase of sulfur dioxide, nitric oxide, carbon dioxide and other polluting gas.

Capital shortage issue needs to be solved.

Achieving the goal of scenario needs a lot of money. By 2020, Jilin City's electricity shortage will reach $170 \mathrm{TWh}$ if there isn't new investment in power generation facilities. 56.4 billion Yuan is required to make up for this gap in the next 10 years, and the required investment will be more if Jilin City expands proportion of low-carbon energy. In conclusion, Jilin City's total investment will be over 100 billion in the next 10 years. It is hard to get the fund only from corporate finance or government support.

\section{Countermeasures of Developing Low-carbon Economy in Jilin}

\section{Macroscopic Countermeasures}

\section{To enhance propaganda and education, to breed low-carbon economy sense.}

At present, the level of public acknowledge of low-carbon economy is still low, so vigorously promoting the public education of low-carbon construction is the important means to cultivate public awareness of low-carbon. On one hand, we need to educate the public on climate change, promoting low-carbon economy and building a low-carbon city through books, newspapers, audio-visual and other mass media, and to promote sustainable low-carbon production and way of life. On the other hand, we should fully make use of modern information technology to further develop and refine the sites construction of climate change and of low-carbon economy. We should release information through the network, disseminate low-carbon knowledge and ideas, and promote low-carbon products.

\section{To complete laws and regulations.}

Laws and regulations of energy production and conversion, energy conservation, solid waste and agroforestry and other fields need to be perfected to reduce carbon emissions. We have to develop and improve the energy efficiency standards, and to strengthen the implementation of energy efficiency standards. The assessment and review of energy efficiency standards and fixed assets investment of industrial, construction and other projects should be combined with each other.

\section{To adjust industrial structure.}

We need to change the current unreasonable industrial structure, gradually form the mature structure of agriculture modernization, steady industry development and service industry rapid development. It is wise to actively develop the services industry to make it become the backbone of economy development and major source of local income, and to changes the industrial structure, which is based on industry, especially heavy industry in Jilin City.

\section{To improve low-carbon technology.}

Improvement of low-carbon technologies relies not only on increasing research investment, but also on introducing foreign advanced technology and experience. Local governments should enhance 
research funding investment and policy support, encourage enterprises and universities and other research institutions to develop new technology, and continue to learn and introduce from international and domestic advanced low-carbon technologies in order to improve technology level of industrial enterprises, especially high energy-consuming companies.

\section{To optimize energy structure.}

We need to actively adjust energy demand structure, and gradually change the energy structure from coal and oil to gas, electricity and heat, especially in Jilin City we should actively develop hydropower. Jilin is one of the a few cities that don't have the problem of water shortage, possession of water resources per capita is 3,679 cubic meters (almost double of the national average level), there is sufficient water resource available.

At the same time, we should actively develop renewable energy and low-carbon energy. Jilin City has rich resources and manufacturing capabilities in renewable energy development. Jilin City in located in the core of Northeast China Power Grid center, which is a big advantage to make use of renewable energy.

\section{To enhance the effects of market mechanism.}

Developing low-carbon economy must make full use of market incentive mechanism. Relying on government's use of compulsory norms and rules and regulations simply can not build sustainable low-carbon economic development power. In contrast, the appropriate introduction of economic incentive mechanism, and the bringing the "invisible hand" into play, can encourage resource conservation and environmental protection consciousness in order to ultimately realize the coordinated development of economic activities and environmental protection.

\section{Microscopic Countermeasures}

To enhance the support of financial institutions to low-carbon economy.

Banks and other financial institutions also generate carbon dioxide emissions during their operations, because the loaning and investing behavior conducted by these financial institutions will have a direct impact on energy consumption and carbon emissions in various industries and projects. Therefore, financial institutions need to explore the establishment of a credit model to respond climate change, to strengthen the administration of financing and investing of low-carbon projects. On the other hand, financial institutions can actively participate in carbon finance market. In accordance with "Kyoto Protocol", developed countries must transfer capital and technology to developing countries to develop low-carbon economy in response to climate change. Financial institutions need to conduct financial system innovation, especially carbon credit system innovation to create the stage for the upcoming carbon finance market.

To make measures to inspire public participation.

Application of incentive theory in the construction of low-carbon city is to adopt incentive measures round the differences between public needs implementation and their needs incentives to fully mobilize the enthusiasm of public participation, for example, to give spirit or material rewards to enterprises or individuals for their active participation in low-carbon cities publicity and construction, to establish a low-carbon concept incentive fund, to carry out pollution reporting system.

\section{To establish low-carbon construction funds.}

We should introduce the successful national integrated environmental fund experience widely used in transitional countries to establish low-carbon construction funds to support low-carbon economy projects. Low-carbon construction funds should be based on government investment, and raise funds through multiple channels, operate according to business mode. Low-carbon construction funds companies should find out carbonneutral techniques through a variety of ways to assess its emission reduction potential and technological maturity in order to encourage technological innovation, develop and foster low-carbon technologies markets, and promote long-term emission reductions.

\section{To promote building energy efficiency.}

On one hand, we need to introduce new energy-saving materials, improve building materials production process, and reduce energy consumption of building products. Government could release 
relevant policies to make real estate development products meet certain "low-carbon quantitative indicators." On the other hand, we should adopt energy-saving and environmental designs in building design and construction, and promote the application of sewage treatment, water reuse, rainwater collection, heat metering, waste disposal, housing and other advanced technologies. We'd better introduce solar power system in residential and commercial architecture. At the same time, the application and popularization of green roofs technology should be considered. Urban green roof is an effective way to save the land, open urban space, improve the living environment, but for most of the cities and buildings, the roof is still being neglected, which is in fact a waste of resources. Therefore, we could support green roof companies and conduct relevant green roof publicity to build a green low-carbon city under the support and help of our government.

\section{To establish "Low-carbon" urban transportation system.}

The most important measure of establishing "Low-carbon" urban transportation system is to promote bicycle travel, which can effectively reduce carbon emissions in transport system, conserve energy, and build green transport. Secondly, we must accelerate the introduction of new hybrid power electric bus to achieve a comprehensive update of the city mass transit system. At present, a few of bus lines have used such kind of buses in Jilin City, and have been recognized by the general public. So the government can take advantage of present development trends to vigorously promote the upgrading of public transportation system, to strictly control the operation of high-consumption and high-pollution vehicles, and to achieve comprehensive low-carbon green development. Finally, we should popularize LED energy-saving lamps in the transport system. LED lamps have the characters such as low voltage, low power-consumption, high luminous efficiency, long service life, and etc. It can save 80\% energy than incandescent, 50\% than fluorescent, and achieve green light.

\section{Testing Measure-Green Use of Carbon Dioxide}

Carbon dioxide is the largest carbon source on earth, and the carbon content of carbon dioxide in the natural world is $1 * 10^{16}$ tons, which is much higher than the carbon content of coal, oil and natural gas. Petroleum chemical industry is the second largest carbon-emission industry that is superior to iron and steel industry, so the green utilization of carbon dioxide has a special meaning for the chemical industry on energy conservation. South Korea has developed a new process to produce methanol by carbon dioxide and hydrogen. Japan is developing the method to produce dimethyl ether by carbon dioxide and hydrogen. Total amount of carbon dioxide recycling in China and application areas both have a wide gap compared with the western countries, so the green use of carbon dioxide is even more significant. Petrochemical economy is in the dominant position of Jilin City, so we must reduce the environmental pollution and hazards operated by petrochemical enterprises through the green use of carbon dioxide.

\section{Summary}

During the analysis of low-carbon economy development status and countermeasures in Jilin City we could find out that Jilin City has full potential to develop low-carbon economy, and actually Jilin City has successfully obtained many achievements. We believe that Jilin City must achieve more significant gains in the future under the brilliant leadership of the local government.

\section{References}

[1] UK Energy White Paper: Our energy future-creating a low carbon economy [Z], 2003.

[2] Donald Hanson. An integrated analysis of policies that increase investments in advanced energy-efficient/low-carbon technologies [J]. Energy Economics, 2004(26).

[3] Kawase,R, Matsuoka, Y, Fujino, J. Decomposition Analysis of CO2Emission in Long-term Climate Stabilization Scenarios[J]. Energy Policy, 2006(34): 2113 2122. 
[4] Koji Shimada, Yoshitaka Tanaka, Kei Gomi et al. Developing a Long-term Local Society Design Methodology Towards a Low-carbon Economy: An Application to Shiga Prefecture in Japan[J]. Energy Policy, 2007(35):4688 4703.

[5] Massimo Tavoni. Forestry and the carbon market response to stabilize climate [J]. Energy Policy, 2007 (35): 5346-5353.

[6] Weifeng Ren. Low-carbon Economy and Financial Innovation [J]. Shanghai Economy Research, 2008(3). 